\title{
Shifts, turning points and inertia exploring long-term industry trends in European transport
}

\author{
Massimo Moraglio $^{1} \cdot$ Hans-Liudger Dienel $^{1}$ \\ Received: 17 June 2015 / Accepted: 5 September 2015 / Published online: 5 October 2015 \\ (C) The Author(s) 2015. This article is published with open access at Springerlink.com
}

\begin{abstract}
In this introduction to the topical collection on the "Future of Transport in Europe", we argue that European transport regimes are at a turning point and despite the sector inertia, we can detect cultural, societal, and technical shifts. In this article, we assume that these shifts are central in defining possible future trends, far beyond their current fragile relevance. Such an analysis steps further into the technological realm, and targets social, industrial and political issues, which could affect the future of transport up until 2050, with a special focus on the post-ownership economy. Thus, we frame both technological innovations and societal shifts, aiming to discuss the future of transport as a socio-technical construction, far beyond the commercial and economic debate. In the conclusion, we report briefly on how two conflicting elements are now relevant for the future of transport, namely inertia and innovation: both can play a significant role in opening up different transport regimes in the future, or tying us to a repletion of old patterns. This article is based on the results of an EU-funded research network (www.race2050.org), which we coordinated.
\end{abstract}

Keywords Transport $\cdot$ Mobility $\cdot$ Europe $\cdot$ Future . Transition $\cdot$ Inertia

Massimo Moraglio

massimo.moraglio@tu-berlin.de; http://www.tu-berlin.de

Technische Universitaet Berlin, Marchstraße 23, Sekr. MAR 1-1, 10587 Berlin, Germany

\section{Background}

Why devote a topical collection of articles to the future of transport in Europe? Is this such a relevant topic, one able to inform us beyond its own core? Moreover, with which tools and approaches can we securitize the futures of such a field up until 2050? As guest editors, we try to address here some of these overarching questions.

Let's start by claiming that transport has been a central issue of European political and social debate post Second World War. Freedom of movement for Europe's citizens has been a source of political struggle, in which the potentiality of a border-free continent should have initiated an era of peace, prosperity and development. The lack of restrictions on movement for EU citizens (and goods) is indeed a pillar of European Union existence, a fundamental issue for its political legitimation and self-representation [27]. For those blessed with an EU passport, visa requirements are today often trivial, whilst border controls inside of the Schengen area are regarded as no more than a historical instance. The ability of goods to move around is even more extensive, considering how nowadays, roughly only $30 \%$ of any final product contains local inputs [39]. In other words, transport is at the core of our everyday life, whatever we perform it as daily commuters, new hyper-mobile nomads or goods' consumers. Transport embeds every interstice of our life, even when we don't move at all.

Transport is also relevant in the definition of European commercial trends and economic sustainability. While many other European industries have suffered from global competition and have declined in the last four decades, such as the textile industry, or have almost disappeared, such as the mining industry, the European transport industry has remained competitive and strong on a global level. This is generally true both for equipment and for services, though with great 
differences from branch to branch. The European transport industry is thus a main contributor to European wealth. As mentioned, openly, by the European Commission, focusing on the automotive industry, such a branch

is central to Europe's prosperity. [...] It is a huge employer of skilled workforce, directly employing over 2 million people but responsible for some 12 million jobs. It is a key driver of knowledge and innovation, investing more than $€ 20$ billion a year in $R \& D$, making it Europe's largest private investor in R\&D. With an annual turnover of $€ 780$ billion and a value added of over $€ 140$ billion, it makes a major contribution to the EU's GDP. It exports far more than it imports, with a surplus of over $€ 60$ billion on overall exports of $€ 125$ billion. [7:3]

The impact of the transport realm does not stop at the political, social or economic levels. Besides economic sustainability, transport systems affect the environment (the transport sector is a growing source of $\mathrm{CO} 2$ emission), creating pollution [8], and also harming human health. According to the World Health Organisation's estimations, in Europe alone, air pollution, in which transport-related emissions are very relevant, is the reason for 800,000 deaths [42]. Amongst others, the Italian health ministry have just published a report, claiming that smog shortens the life of citizens in Italy by 10 months [38]. We could also mention that there is an energy issue here, as the transport sector is heavily dependent on fossil fuels, and thus a great contributor to the dependency of Europe on fossil fuel imports [7]. On the other hand, we should mention the need of new infrastructural investments in order to keep our transport systems functioning properly, investments that Europe today finds difficult to provide [28].

The analysis of the future of transport is therefore central in assessing Europe's core and long-term political and social issues, including those regarding political trends, social polarization and economic sustainability. If these are the issues, which instruments can we employ to face these challenges?

Different institutions of the European Community developed or funded a number of important transport foresight studies. After the fall of the Iron Curtain and during the 1990s, European transport policy was focusing on facilitating intermodal transport, achieving modal-shift, implementing the Trans-European Transport Networks (TEN-T), introducing transport pricing and reducing the environmental impacts of transport. This focus is still visible in the EC 2001 White Paper European transport policy for 2010: time to decide [6]. Shortly after publication, the $9 / 11$ terrorist attacks in the United States and the sharp jump in oil prices brought further priority issues to the agenda of transport policy making. The security of energy supply and - once more - the necessity of a rapid shift from a fossil fuel based transport system to a transport system based on a diversity of energy sources, mainly renewable.

Thus, there are some dozen serious long-term foresight studies on the future of transport at a European level and at different national levels on our bookshelves. Most studies do not only foresight (or forecast, predict, extrapolate) but they aim at developing specific policies to reach a stronger, greener, less CO2-intensive and more user-friendly transport industry. Some of the results presented here are the outcome of research funded by the European Union's FP7 programme, entitled RACE2050 - Responsible innovation Agenda for Competitive European transport industries up to 2050 (www.race2050.org).

Looking at the future European agenda for transport, three elements are particularly relevant.

1. The 2011 White Paper on Transport, as published by the European Commission; that is a sort of normative scenario, aiming at a sharp reduction of transport-related $\mathrm{CO} 2$ emission for 2050. Such a clear and ambitious focus has driven debate and research paths.

2. The European Technology Platforms (ETPs), which "are industry-led stakeholder fora that develop short- to longterm research and innovation agendas and roadmaps for action at the EU and national level to be supported by both private and public funding" [9]. The transport sector has five ETPs, which are gaining greater ground in the debate.

3. The role of "transition" toward new transport regimes and the launch of a new research agenda in the EU H2020 for 2014-2020. The concept of backing research and action towards the transition to new transport regimes was shown in the first call for 2014-2015, but is more evident in draft of the programme for 2016-2017 [10].

While largely focused (or even obsessed) with technocratic approach, ${ }^{1}$ the debate is actually becoming more aware, also in academia and amongst European policy-makers, of other aspects. The social sciences are stepping into the debate, whilst transport planners and experts are more aware of the soft side of travelling and the weakness of the "predict and provide" model. Some novel social attitudes are re-shaping traditional transport systems, influencing the sector and, rather relevant for future trends, paving the way for paradigmatic shift [30]. And, last but not least, wild cards' analysis is finally on the stage, an issue discussed on this topical collection in the article by Hauptman, Hoppe and Raban [15].

We should thus frame technological achievements within a broader picture, in which other factors, including lifestyle

\footnotetext{
1 "Technological innovation will be a major contributor to the solution of transport challenges. New technologies will provide new and more comfortable services to passengers, increase safety and security and reduce environmental impacts" [7:18].
} 
trends and social attitudes, influence transport. The need of a larger pool of factors is indeed one of the fil rouge that guides the whole topical collection, and this is even more evident in the article by Tuominen, Wessberg and Leinonen [35] as well as in the one by Kammerlander, Schanes, Hartwig, Jäger, Omann and O'Keeffe [22].

For instance, it seems banal to say that transport regimes can change according to new social and economic patterns, working conditions and social organisation. All those elements can stress current transport systems, or catalyse new requests. There is no doubt that transport choices follow mostly economic rationale. But - as with any other human activity mobility is also embedded with symbolic, political and social values [29]. Transport preferences are not only therefore the mere result of the best resource and time allocation; those preferences are influenced by social relevance and individual taste. Transport therefore has to be understood as a relevant human activity well beyond the simple need to move from A to $\mathrm{B}$, because it leads also to the representation of self and to more symbolic targets [41]. In other words, transport provides answers to prosaic needs for movement, but it is also an emotional and symbolic issue.

It is therefore useful to better understand transport facilities and systems by introducing the concept of "mobility culture". We can depict "mobility culture" as the "use of transportation and, by definition, of space, the type of vehicle and its equipment, the fun it brings, or the rationality of ownership and the skills that go with it." [5]. Naturally, mobility culture can be claimed to be both plural and changeable according to personal choices, as well as social, geographical and historical constraints. Due to this, we can say we have different mobility cultures and consequently, mobilities sub-cultures. This fragmentation of attitudes and cultures amongst final-users of transport, however, does not impede the establishment of a (socially and politically constructed) dominant mobility culture. Regarding Europe, with no distinction between east and west or north and south, the motor-vehicle regime has been indisputably claimed as the way of moving [37]. This choice has been challenged daily through fuel costs, congestion, lack of parking facilities, pollution concerns, and cultural criticism [24]. Despite the car's failure to maintain its promises (easier, individual, faster and more comfortable movements), motorvehicles are still enjoying their role as the leading mode of transport [13]. Not only have they maintained their prevailing position in mature economies, but they are also growing virally in emerging economies. The relation between the "old" automobile socio-technical system and the "new" autonomous motor vehicles is, for instance, addressed, among other topics, by the articles written by Thomopoulos and Givoni for this topical collection, who stress the persistency of the transport culture. In addition, Fraedrich, Beiker and Lenz [12] in their contribution urge us to take care of the social acceptance of new culture as a fundamental step for innovation.
On the other hand, deep social shifts, new labour conditions, income polarization and new life-styles associated with growing pressure regarding environmental concerns, are catalysing new mobility concepts, with people paying greater attention to "alternative" systems of mobility. Here we have a contradiction between inertia and change, an issue that will be further developed in the conclusions of this article. It is true that car-culture has undoubtedly lost its appeal, but it is still dominant. However, as the same car industry is carefully detecting, we are witnessing some new social patterns and behaviours, especially in Europe, which can harm, in the long run, such a supremacy [20].

\section{Sharing economy as future pacesetters?}

We are aware that some social, economic and environmental patterns are defined as megatrends: urbanisation, ageing societies, or, closer to the transport field, growing global mobility demand, energy constraints and environment concerns [34]. There is little doubt that these megatrends will influence the transport regimes of the future, though the shape of such an influence is naturally rather questionable. As the article written for this topical collection by Julsrud and Uteng [21] also show, other social trends, business models and technological achievements are less prone to be framed as such: for instance, the understanding of lack of funding in Europe (and broader in mature economies) for infrastructure is gaining momentum, giving very little indication about its next move, and even less about their influence on European transport systems. We can define these feeble developments, currently in their embryonic stage, as cultural, economic or social shifts, so far still "weak signals". ${ }^{2}$ These shifts, often, like megatrends, can be factors external to the transport field, thus opening up a broader perspective of analysis.

Among other novel elements, the impact of the so-called post-ownership economy in the transport field indeed has a crossover effect in many various ways [4], which range from the decline of car purchase in Europe to the development of para-transit (e.g., passengers' not-scheduled services). Its effect goes further, nudging to the implementation of new transport system organisation. Finally yet significantly, a postownership economy is one of the reasons behind new transport regimes and new business models. In other words, the rise of sharing-economies is openly challenging dominant transport culture, e.g., the motor-vehicle own-and-use attitude, which has been dominant for the past 80 years in Europe.

\footnotetext{
${ }^{2}$ For "Weak signal", we indicate new patterns that are so far still at niche stage. As largely accepted in the future research arena, in "recent years the concept of weak signals and emerging issues has come to the attention of researchers publishing in strategy literature and in literature on futures studies, and as a special interest among researchers and consultant as a tool for anticipating change." [16]
} 
The transport industry is well aware of this, addressing the challenge of new social attitudes and the rise of postownership economy in many different ways. The final outcomes of innovative behaviours and lasting classical models can indeed be a mish-mash of new and old transport offers, in which different customers, according to their cultures, can find the right deal.

For the moment, two ground-breaking elements are emerging as a consequences of post-ownership economy: i) the industry shifting from selling to service and ii) the integration of transport regimes and markets.

\section{The industry approach: shifting from selling to services}

The European industry is fully engaged with the concept of sharing economy, which has to be encompassed in a wider narrative, including the decline of motor vehicle use (both as driver and passenger) and a declining number of driver's licenses requested by young European generations. On top of that, it is solidly assessed that in mature economies society is shifting to post-ownership economy, at least in some service and products (for information on car peak and its controversial analysis see also the contributions part of this topical collection). This tendency is more evident in younger generations, or the so-called "Generation Y", and car ownership is highly affected by new attitudes and new behaviours [4]. Focusing on car ownership, with a broader perspective "near the end of the 1975-2010 period, most advanced economies experienced a slowdown in the relationship between income growth and vehicle ownership expansion. This does not mean that 'saturation' levels of ownership (meaning that further income growth would not translate into higher ownership rates) have been reached, but it is highly plausible that further income growth will have ever more limited impacts on the expansion of the stock" [19].

Therefore, it has been envisioned that

the consumer of 2020 is more likely to be interested in flexible access to different types of transport. Primary ownership profiles are likely to shift to the small luxury segment in line with 'median needs' (primary daily needs). Bundled in the price would be scalable access to additional vehicles. Lifestyle changes will allow access to luxury or larger vehicles during weekends, as an example, while a small, efficient vehicle will suffice for daily commuting needs. This model would impact the aggregate production profile for vehicle segments. The other part of this equation is the integration of multiple modes of transport. The emergence of "mega cities" and the growth in public and alternative transport options will be a key influencer to changing lifestyles. This will necessitate the creation of a seamless mobility experience between automobiles and these alternatives. [17]

This new landscape is having an increasing impact on the automotive sector, pushing the industry to cope with such a change. New business models are thus addressing this shift, "from enhanced services to leasing and mobility service provisions, these are taking root and providing new market opportunities as [automotive] Original Equipment Manufacturers (OEM) seek to reinvent themselves in a changing mobile market. Significant potential exists for OEMs and suppliers to engage with the following auto market trends" [11]. The core concept here is that, whilst car ownership is losing appeal, “most consumers don't want to give up access to vehicles" still. This means that the "automakers are challenged to bundle the right mix of cars and other transport modes into compelling, integrated new offerings." [18]

Some European brands are making big efforts to cope with these segmented markets. Daimler Financial Services, for instance, "plays a major role in supporting our vehicle sales by offering customised financial services for everything related to automobiles. The comprehensive range of financing, leasing, insurance, fleet management, banking and mobility services makes it easier for private and commercial customers to enter the world of our premium automobiles, and also ensures longterm customer loyalty to our brands around the globe" [3]. Additionally, Daimler is developing, with Europcar (the car rental company), car2go, a car-sharing company, with a fleet of premium electric-vehicles. Naturally, Daimler is only one of the OEMs active in the car-sharing scheme. Quicar by Volkswagen, DriveNow by BMW, Multicity by PSA and Renault-Way (just to mention a few) can be counted as similar initiatives, which can be run in alliance with car-rental firms (as for Daimler and BMW), or independently.

What seems to be an automotive problem limited to mature economies is, actually, a global question that concerns all the transport sectors. Surely, car manufacturers are in the most vulnerable position, and "auto industry companies are determining how to stake their claim in emerging mobility services business models, as congestion, population growth and pollution issues push consumers to consider the limitations of vehicles" [18]. However, not only motor-vehicle manufacturers, but all transport operators are implicated in these new trends. As seen above, airlines and railways operators, carsharing and car-rental firms, urban transit suppliers and logistical operators are broadening their horizons and moving towards a more varied range of offers. The shrinking rate of car ownership is a relevant element, and once associated with a flexible, supple and personalised travel scheme (supported by ICT) is now generating a new travel attitude and is thus reshaping the transport market. So, while Daimler developed Moovel as an end-to-end personal travel manager [3:85], 
Deutsche Bahn has its Fahrplanservices (travel planner service) application.

Therefore, not only the manufacturing industry is preparing itself for these future expectations. As reported by Sixt, a car rental company, in its Annual Report 2012, "the company offers its customers tailor-made products that provide mobility of a few minutes to several years", stressing how the mobility market can largely vary according to "a modern and comprehensive concept of mobility" [31].

\section{Shifting towards transport regimes integration}

A less recurrent, but relevant challenge is the need for higher integration of different transport services and modes to respond to a comprehensive mobility demand of users. The idea of a seamless journey, which reduces the changes of mode, shrinks the time-budget necessary for a given trip, whilst offering greater comfort and reliable performance, is naturally the desire of any traveller. Timetable coordination (ability to conjugate different transport modes and operators), information desks, information displays have all been the first steps towards such a target. Naturally, the trend towards smoother travel found formidable barriers in the lack of coordination amongst different systems, also due to the lack of incentives for many operators [25]. National borders, languages differences and other framework conditions offered further challenges.

However, ICT development, inter- and intra-modal competition made it possible - both in technological and business spheres - to have better results and less fragmented journeys. In this vein, passengers' awareness about the constraints of their time-budget and energy concerns provided a pushing factor to achieve such a goal. Indeed, the issue of a smoother journey and a greater attention to customers' satisfaction became more and more present in the political, social and economic debate in the past decade [40].

Such coordination amongst modes and companies has often been implemented by public agencies, sometimes with excellent results, but often the coordinating bodies were not able (or truly interested) in developing a fruitful coordination [25]. Naturally, market forces are also developing products concerning this niche, starting to offer more and more doorto-door information and, eventually, services. According to the first-mover advantage concept, the first operator able to offer those services, gain a dominant position. The role of start-ups and peer-to-peer non-profit associations in this innovative market is very relevant, comparable to the ICT industry.

Altogether, the boundaries amongst the players are less certain and more blurry, and the automotive industry seems to be leading this process. The OEMs and researches point out how motor-vehicle manufacturers are re-thinking, strategically, their missions and their business. As reported by a German study,

Conventional notions of the role of the traditional OEM within the automotive industry value chain are slowly but surely being consigned to the past. The classic OEM business model - with its dependence on turnover generated from new vehicle sales - is undergoing a major paradigm shift as value creation returns continue to fall. Not only is the modern driver more discerning in his or her auto-purchasing behaviour, but heightened buyer expectations have created a market in which there is a car for every consumer. As a result, OEMs have found themselves caught up in a "crowding-out" cycle where evermore and better technological features are required to stay ahead of a congested international market. [14]

Surely many companies are still mainly interested in their core business, but a larger number of firms are breaking boundaries, stepping into other segments (and new markets), acting with innovative business solutions. In other words, the industry is entering into a stage characterised by a "holistic" approach concerning mobility, in which the hurdles amongst transport sectors are weak or vanishing [39]. The tendency to cover a multitude of sectors and sub-sectors is not completely new. In the 1930s Fiat advertised itself as a "Terra Mare Cielo" [Land Sea Sky] company, considering Fiat manufactured cars, trains, ships and aircrafts, covering all transport segments, not to mention that FIAT also owned several bus companies, built, owned and operated a motorway, and had its own car insurance company, as well as a financial branch for car leasing [2]. Moreover, alongside the vertical and horizontal integration of the Ford Company in the 1930s [1], several European national public-owned railway companies developed road freight transport branches.

The question we should therefore address is which are the real novelties of today's industry and market trends (compared to the past), and how will such a process impact the EU transport industry. Two main factors can be detected. The first one is the role of ICT in supporting and back this trend. ICT is catalysing this process, offering innovative tools that facilitate such a trend. Actually, some mega ICT companies, like Google, are taking advantage of this and are developing economies of scale, as in the case of Google maps, exploited for driver-less vehicles [32]. The second one is the need to use existing infrastructure and devices better, and this due to money- and time-budget constraints, as well as energy, pollution and infrastructural worries. The core of integrated passenger transport is presented in three clusters as follows:

- Inter-modality concepts combine the strengths of different transport modes to increase flexibility and efficiency without compromising reliability and comfort. Research 
focuses on aspects such as barriers to interconnectivity of transport networks, integrated transport planning, physical integration of infrastructure and services.

- Integrated passenger information focuses on smart solutions to meet information needs of passengers before and during multimodal journeys, such as schedules, trip planning, and ticketing across transport modes.

- Platforms for intermodal coordination support coordination of transport operators and terminal managers in providing integrated transport services. Research covers information platforms, interoperability of information and ticketing systems, and standards for physical interoperability. [33]

The above targets are not only business opportunities, but also highly requested in order to increase the efficiency of overall transport services. Efficiency here has to be understood as energy reduction, environmental concern and as better exploitation of already existing transport systems. Thus,

since demand for passenger transport is expected to increase further in the coming decades, more efficient use of existing capacity is vital in maintaining the performance of the passenger transport sector. This requires better connection between transport modes and better use of each mode's comparative advantage. Integrating and combining transport modes based on their comparative advantages enables more efficient use of the transport system as a whole and offers a wider range of alternatives in passenger transport. [33]

Such a situation has been seen as a great opportunity for many companies, a situation that can lead to a completely new industry panorama. For instance, the rail manufacturing industry aims to move from selling just products to selling services, as has happened for other sectors: "In other infrastructure sectors such as telecommunication, differentiation can in extreme cases even lead to switching from selling assets to becoming a service provider, offering accessibility as a service to the previously sold assets" [36].

\section{Conclusion}

As readers will discover in the articles section of this topical collection, ground-breaking technological innovations, societal shifts and climate changes are at the core of the works presented here: new artefacts (like autonomous cars), new fuels, new social attitudes. However, another element is subtly present, namely the strong inertia witnessed by transport regimes, which are in Europe, generally speaking, the same as 80 years ago. As widely debated in the articles composing this topical collection, the two elements are part of the same transport regime, influencing and shaping each other, considering how the elements of innovation are crashing/dealing/ disguised with long-durée trends (and vice versa).

A better understanding of the future of transport in Europe seems to be more urgent nowadays than ever, considering the overall challenges as profiled on the horizon. Indeed, it seems, even to non-experts, that there are a lot of changes and shifts in the transport realm. The full capacity of ICT is still ahead, especially once driverless vehicles enter the scene. Cars' electric engine development is now placed in the "disillusion valley" after past enthusiasms, but is it maybe just a hurdle before its steady? The transition towards new energy and transport regimes is called into question more and more insistently, calling for the end of automobility as it is known today [13]. The transport industry landscape is witnessing radical changes, in which China is not only the biggest motorvehicle market, but also the biggest car manufacturer. European final-users' behaviours are shifting: sharing economy, post-rush attitude, fragmented lives are highly influencing transport systems and its industries, both on the sides of manufacturing and service.

The very same tools for scrutinizing this unsettled situation are under transformation. Transport has been considered a mere technological artefact, to be cared by the wisdom of technical professional experts, namely engineers, planners and some other "happy few" holding highly-specialised skills. In the past two decades, social sciences stepped into the debate, whilst transport planners and experts are more aware of the soft side of travelling and the weaknesses of the "predict and provide" model. The very same pillar of past transport policies, investment choices and the rationales of transport regimes have been investigated in an innovative way. For instance, amongst others, infrastructural investment policies based on passengers' timesaving have been convincingly criticized [26].

Finally, the use of transport and the core concept of mobility is highly debated. Whilst the ability of movement has been usually considered as an opportunity, we are witnessing a cultural shift in which mobility is considered often as a burden more than a pleasure. Highly fragmented life routines, frantic everyday schedules and "forced" hyper-mobile attitudes are the first symptom of a crisis, in which the journey is not longer a life experience, but a loss of identity. This is undermining the very concept of travelling, as shaped after the Age of Enlightenment [23].

However, there are plenty of counter examples showing a very static situation: inertia seems to be the core concept of transport systems. The current state of the art European transport system was set - to cut a long story short - in the 1930s. The core concepts which permit today mass motorisation (including motorways, close-body cars, traffic lights, etc., that is its whole socio-technical system) were conceived, tested and developed during (or before) that decade. Not to mention 
railway networks, which were already defined before the end of 19th century; "high-speed" trains were already tested in the 1920s. Altogether, with the exception of turbine-powered airplanes and standardised containers in the shipping industry, transport technology is not so much more developed from that of a century ago. The same can be said about the time we spend traveling, which is more or less, on average, $1 \mathrm{~h}$ [43]. We travel further, and faster, but not necessarily longer. And, actually, the past decades have seen the re-birth of "old" and "obsolete" transport modes, like bicycle and tram, which are a great reminder that transport development is not necessarily a progressive tale.

The long-term resilience of 1930 s socio-technical transport systems, despite our current awareness of negative side effects (congestion, pollution and energy cost), shows also the path-dependency of the whole transport sector, which seems locked into the (future) repetition of its past. Innovative, ground-breaking technological artefacts seem not to be so different from previous models: electric motor-vehicles are, at the end of the day, like old familiar cars, with a different engine, whose final effect on pollution and total energy consumption are not so clear. If we look at the strength of changes and the power of inertia, investigating transport trends forces us to move carefully around these two concepts. An enthusiastic appraisal of the ICT impacts on transport systems can be misleading: the success of driverless cars is not granted. Legal or social impediments can block its development. Or, more simply, the pleasure of driving can be a forgotten but crucial issue in the making of driverless car development. This, by the way, opens the question of the role of technology in shaping transport systems, systems that rely also on societal attitudes, behaviours and beliefs.

On the opposite hand, an overestimation of the past can lead us to interpret the future with only the lens of history, which is wrong but also not appealing at all. Environmental challenges and energy issues are questions too big to be ignored once we discuss the future of transport. We thus suggest keeping the ambiguous relationship between innovation and inertia in mind as a core concept for the reading of this topical collection. Indeed, the European transport future appears sometimes to be a moving target, which can offer unexpected and dramatic changes.

We should summarise that the transport landscapes is under change, both in its everyday practice and in their theoretical conceptions. The resurgence of "old" transport modes (like bikes and tramways), the rise of sharing economies (carpooling, car-sharing), and the crisis of car culture are simply the more evident signs of a deep shift in European transport practices. There are, in these trends, enough clues to claim that also in the study of transport and mobilities, linear and progressive stories, usually based on technological achievements, should be looked at with care and not taken for granted.

Disclaimer The research leading to these results received funding from the European Union's Seventh Framework Programme (FP7/2007-2013) under grant agreement no.314753 (Project title RACE2050 - see also www.race2050.org and www.transport-synopsis.eu).

Open Access This article is distributed under the terms of the Creative Commons Attribution 4.0 International License (http:// creativecommons.org/licenses/by/4.0/), which permits unrestricted use, distribution, and reproduction in any medium, provided you give appropriate credit to the original author(s) and the source, provide a link to the Creative Commons license, and indicate if changes were made.

\section{References}

1. Bonin H, Lung Y, Tolliday S (eds) (2003) Ford, 1903-2003: The European History. 2 vols. P.L.A.G.E, Paris

2. Castronovo V (1999) Fiat 1899-1999. Un secolo di storia italiana. Milano, Rizzoli

3. Daimler (2013) Annual Report 2012. http://www.daimler.com/ Projects/c2c/channel/documents/2287152 Daimler_Annual Report_2012.pdf. Accessed 30 May 2015

4. Deloitte (2012) Fourth annual Gen Y automotive survey.Executive summary of key themes and findings. http://www.deloitte.com/ assets/Dcom-UnitedStates/Local\%20Assets/Documents/us_auto_ GenYSurveyReport 02032012.pdf. Accessed 31 May 2015

5. DG-Internal (2010) The Future of Mobility in the EU. DirectorateGeneral for Internal policies, Brussels

6. EC (2001) White Paper. Roadmap to a Single European Transport Area. Towards a competitive and resource efficient transport system. European Commission, Brussels

7. EC (2009) COMMUNICATION FROM THE COMMISSION 104 "Responding to the crisis in the European automotive industry". http://eur-lex.europa.eu: http://eur-lex.europa.eu/LexUriServ/ LexUriServ.do?uri=COM:2009:0104:FIN:EN:PDF. Accessed 30 May 302015

8. EC (2011) Roadmap to a Single European Transport Area Towards a competitive and resource efficient transport system. European Commission, Brussels

9. EC (2013) STRATEGY FOR EUROPEAN TECHNOLOGY PLATFORMS: ETP 2020. ftp://ftp.cordis.europa.eu: ftp://ftp. cordis.europa.eu/pub/etp/docs/swd-2013-strategy-etp-2020_en. pdf. Accessed 30 May 2015

10. EC (2015) Smart-green-and-integrated-transport. http://ec.europa. eu/programmes/horizon2020/en/h2020-section/smart-green-andintegrated-transport. Accessed 15 Juni 2015

11. Forum automobile and society (2012) The European automotive industry at a competitive cross-road: what policy, innovation and jobs for the future? http://www.autoandsociety.com/download/ newsletters/15_05_2012.pdf. Accessed 15 May 2015

12. Fraedrich E, Beiker S, Lenz B (2015) Transition pathways to fully automated driving and its implications for the sociotechnical system of automobility. Eur J Futures Res 3:11

13. Geels F, Kemp R, Dudley G, Lyons G (2012) Automobility in Transition? A Socio-Technical Analysis of Sustainable Transport. Routledge, New York

14. Germany Trade \& Invest (2012) The Automotive Industry in Germany. Issue 2012/2013. http://www.gtai.de/GTAI/Content/EN/ Invest/_SharedDocs/Downloads/GTAI/Industry-overviews/ 
industry-overview-automotive-industry.pdf. Accessed 10 May 2015

15. Hauptman A, Hoppe M, Raban Y (2015) Wild cards in transport. Eur J Futures Res 3:7

16. Hiltunen E (2010) Weak Signals in Organizational Futures Learning. http://epub.lib.aalto.fi: http://epub.lib.aalto.fi/pdf/diss/ a365.pdf. Accessed 30 May 2015

17. IBM (2008) Automotive 2020 - Clarity beyond the chaos. http:// www-935.ibm.com/services/us/gbs/bus/pdf/gbe03079-usenauto2020.pdf. Accessed 03 May 2015

18. IBM (2011) Digital Transformation in the Automotive Industry. Executive summary. http://public.dhe.ibm.com/common/ssi/ecm/ en/gbe03409usen/GBE03409USEN.PDF. Accessed 15 april 2015

19. ITF (2012) Transport Outlook 2012. http://www. internationaltransportforum.org/Pub/pdf/12Outlook.pdf. Accessed 30 May 2015

20. Jeekel H (2013) The Car-dependent Society: A European Perspective. Ashgate, Farnham

21. Julsrud TE, Uteng TP (2015) Technopolis, shared resources or controlled mobility? A net-based Delphi-study to explore visions of future urban daily mobility in Norway. Eur J Futures Res 3:10

22. Kammerlander M, Schanes K, Hartwig F, Jäger J, Omann I, O’Keefle M (2015) A resource-efficient and sufficient future mobility system for improved well-being in Europe. Eur J Futures Res 3:8

23. Kaufmann V (2002) Re-thinking Mobility: Contemporary Sociology. Ashgate, Farnham

24. Ladd B (2008) Autophobia. Love and Hate in the Automotive Age. The University of Chicago Press, Chicago

25. Mees P (2010) Transport for Suburbia. Beyond the Automobile Age. Earthscan, London-Washington

26. Metz D (2008) The Myth of Travel Time Saving. Transport Reviews: A. Transnational Transdisciplinary J 28(3):321-336

27. Misa T, Schot J (2005) Inventing Europe: Technology and the Hidden Integration of Europe. History Technol: An Int J 21(1):1-19

28. OECD (2012) Strategic Transport Infrastructure Needs to 2030. http://dx.doi.org/10.1787/9789264114425-en. Accessed 10 May 2015

29. Seiler C (2009) Republic of Drivers. A Cultural History of Automobility in America. University of Chicago Press, Chicago
30. Sheller M, Urry J (2006) The new mobilities paradigm. Environ Planning A 38:207-226

31. Sixt (2013) Annual Report 2012. http://ag.sixt.de/fileadmin/ downloads/finanzen/geschaeftsberichte/Sixt-Annual-Report-2012. pdf. Accessed 10 May 2015

32. Thomopoulos N, Givoni M, Rietveld P (2015) ICT for Transport: Opportunities and Threats. Edward Elgar, Cheltenham

33. Transport-research.info (2013) Passengers Transport. http://www. transport-research.info/Upload/Documents/201211/20121123 135227_97140_TRS04.pdf. Accessed 30 May 2015

34. TransVisions (2009) TransVisions Main Results. http://www.mcrit. com/transvisions/mainresults.html. Accessed 30 May 2015

35. Tuominen A, Wessberg N, Leinonen A (2015) Participatory and prospective value network analysis: supporting transition towards biofuels in Finnish road transport. Eur J Futures Res 3:6

36. UNIFE (2010) World Rail Market Study. Status quo and outlook 2020. UNIFE, Brussels

37. Urry J (2007) Mobilities. Polity Press, Malden

38. VIIAS (2015) La Valutazione Integrata dell'Impatto dell'Inquinamento atmosferico sull'Ambiente e sulla Salute in Italia (VIIAS). http://www.viias.it/wp-content/uploads/2015/06/ VIIAS-4giugno2015-per-stampa-CA.pdf. Accessed 10 June 2015

39. WEF (2012) Outlook on the Logistic \& Supply Chain Industry 2012. Rhttp://www3.weforum.org/docs/WEF_SCT_GAC OutlookLogisticsSupplyChainIndustry_IndustryĀgenda_2012. pdf. Accessed 10 June 2015

40. WEF (2013) Connected World. Transforming Travel, Transportation and Supply Chains. http://www3.weforum.org/ docs/WEF MO ConnectedWorld Report 2013.pdf. Accessed 30 May 2015

41. Wollen P, Kerr J (2002) Autopia. Cars and culture. Reaktion Books, London

42. World Health Organization (2013) Review of evidence on health aspects of air pollution - REVIHAAP Project. http://www.euro. who.int/_data/assets/pdf_file/0004/193108/REVIHAAP-Finaltechnical-report-final-version.pdf. Accessed 30 May 2015

43. Zahavi Y, Talvitie A (1980) Regularities in travel time and money expenditures. Transp Res Rec 750:13-19 